\title{
Market Survey and Analysis of Packaging Information Provided by Different Pharmaceutical Companies of Bangladesh
}

\author{
Shibtosh Sarker ${ }^{1}$, Arindom Pal $^{2}$ and Jesmin Sultana ${ }^{3}$ \\ ${ }^{1}$ Department of Pharmaceutical Technology, University of Dhaka, Dhaka-1000, Bangladesh \\ ${ }^{2}$ Department of Pharmacy, East West University, Aftabnagar, Dhaka, Bangladesh \\ ${ }^{3}$ Department of Business Administration, University of Asia Pacific, Dhaka, Bangladesh
}

\begin{abstract}
The purpose of the present study was to investigate whether or not the pharmaceutical companies of Bangladesh are providing all the necessary information and instructions in the packaging materials of pharmaceutical products which are available in Bangladesh. With this aim, the sample of secondary packaging material (cartons, labels, inserts or direction slips) of a total 150 products (from 50 generics) marketed by 15 pharmaceutical companies have been selected and were collected from different medical stores of Dhaka city. The packaging materials of the collected samples were then evaluated based on various regulatory and clinical parameters. It was found that some of the packaging materials of these selected pharmaceutical products lack several important information in terms of clinical and regulatory parameters which limits the quality of these packaging materials.
\end{abstract}

Key words: Secondary packaging material, carton, insert, direction slip, label.

\section{Introduction}

As human being we have the fundamental right to have access to health services. While viewing the health related issues we are hardly conscious about any medicine or drug. Now a days mass people collect medicines around the world with or without the prescription of the physicians. In Bangladesh the tendency of the mass people to buy medicines without proper prescription is increasing day by day. This may create serious health hazards for them. In our country chemists (dispenser of medicine store) without having proper knowledge regarding medicine plays a very vital role in dispensing drug products. As a large number of our people live under the poverty line and have limited access to registered physicians, they usually depend on the chemists for prescribing and purchasing medicines. There is huge number of chemists in Bangladesh who read the packaging information of medicines to dispense drug products to the customers. So information in the packaging of pharmaceutical products is very important both for patients and drug dispenser (European commission enterprise and industry directorate-general 2008). On the other hand, the pharmaceutical market of Bangladesh is growing faster. The total size of the pharmaceutical market of Bangladesh was estimated 8,404 Cr. Taka (approx.) in 2011 with a growth of $23.59 \%$ (IMS Health, 2011). There are more than 235 small, medium, large and multinational pharmaceutical companies producing around $97 \%$ of the total drugs (Directorate General of Drug Administration 2012). The pharmaceutical companies of Bangladesh are producing drugs from almost all therapeutic classes. Among them Antiulcerants, Cephalosporins \& Combinations, NonNarcotic Analgesics, NSAIDs, Macrolides \& Similar Type, Fluoroquinolones, Anti-Epileptics, Antihistamines, and Broad Spectrum Penicillins, Tranquillizers (IMS Health, 2011) are mentionable and their market size is growing day by day.

Packaging can be defined as an economical means of providing presentation, protection, identification information, containment, convenience and compliance for a product during storage, transport, display and until the product is consumed. Packaging must provide protection against climatic, physical and chemical hazards and must be economical. The package must ensure adequate stability of the product throughout the shelf life (European Pharmacopoeia, 4th Ed.).Packaging is a critical tool in the pharmaceutical industry for product delivery 
and regulatory compliance. The external image of the package must not only compliment product confidence, but also provide clear and concise product identification and other features which include:

- Package should provide adequate information related to the contents including legal requirements, storage conditions, batch number, expiry date, and manufacture's name and address and product license number.

- Brief clinical information.

- Package should assist in patient compliance.

- Package should preferably have an aesthetically acceptable design.

The primary packaging consists of those packaging components which have a direct contact with the product (i.e. bottle, cap, cap liner, foil, container etc). The main functions of the primary package are to contain the drug and to restrict any climatic, chemical or occasionally mechanical hazards that may cause damage of the product and lead to product deterioration. Packaging may also act as a means of drug administration. The packaging outside the primary package is known as the secondary packaging. The secondary packaging mainly provides additional physical protection necessary to endure the safe warehousing and for refill packaging. The kind of packaging and the materials used must be chosen in such a way that:

- The packaging itself does not have an adverse effect on the product (e.g. through chemical reactions, leaching of packaging materials or absorption), and

- The product does not have an adverse effect on the packaging, changing its properties or affecting its protective function (WHO 2002).

A packaging system found acceptable for a drug product is not automatically assumed to be appropriate for another. Each application should contain enough information to show that each proposed container closure system and its components are suitable for its intended use. The type and extent of information that should be provided in an application will depend on the dosage form and the route of administration. For example, the kind of information that should be provided about a packaging system for an injectable dosage form or a drug product for inhalation is often more detailed than that which should be provided about a packaging system for an oral solid

Table 1. Types of primary and secondary packaging material (Review On: The Pharmaceutical Packaging 2012)

\begin{tabular}{|c|c|c|}
\hline Material & Type & Example of use \\
\hline Glass & Primary & $\begin{array}{l}\text { Metric medical bottle, ampoule, } \\
\text { vial }\end{array}$ \\
\hline \multirow[t]{2}{*}{ Plastic } & Primary & $\begin{array}{l}\text { Ampoule, vial, infusion fluid } \\
\text { container, dropper bottle }\end{array}$ \\
\hline & Secondary & Wrapper to contain primary pack \\
\hline Cardboard & Secondary & Box to contain primary pack \\
\hline Paper & Secondary & Labels, patient information leaflet \\
\hline
\end{tabular}

Table 2. Examples of Packaging Concerns for Common Classes of Drug Products (MP DiVito et al, 1992)

\begin{tabular}{|c|c|c|c|}
\hline $\begin{array}{l}\text { Degree of Concern } \\
\text { Associated with the } \\
\text { Route of } \\
\text { Administration }\end{array}$ & \multicolumn{3}{|c|}{$\begin{array}{l}\text { Likelihood of Packaging Component-Dosage } \\
\text { Form Interaction }\end{array}$} \\
\hline Highest & $\begin{array}{l}\text { High } \\
\text { Inhalation } \\
\text { Aerosols and } \\
\text { Solutions; } \\
\text { Injections and } \\
\text { Suspensions }\end{array}$ & $\begin{array}{l}\text { Medium } \\
\text { Sterile } \\
\text { Powders } \\
\text { and } \\
\text { Powders } \\
\text { for } \\
\text { Injection; } \\
\text { Inhalation } \\
\text { Powders }\end{array}$ & Low \\
\hline High & $\begin{array}{l}\text { Ophthalmic } \\
\text { Solutions and } \\
\text { Suspensions; } \\
\text { Transdermal } \\
\text { Ointments and } \\
\text { Patches; Nasal } \\
\text { Aerosols and } \\
\text { Sprays }\end{array}$ & & \\
\hline Low & $\begin{array}{l}\text { Topical Solutions } \\
\text { and Suspensions; } \\
\text { Topical and } \\
\text { Lingual Aerosols; } \\
\text { Oral Solutions and } \\
\text { Suspensions }\end{array}$ & $\begin{array}{l}\text { Topical } \\
\text { powders } \\
\text { Oral } \\
\text { powders }\end{array}$ & $\begin{array}{l}\text { Oral } \\
\text { Tablets } \\
\text { and Oral } \\
\text { (Hard and } \\
\text { Soft } \\
\text { Gelatin) } \\
\text { Capsules }\end{array}$ \\
\hline
\end{tabular}

dosage form. More detailed information usually should be provided for a liquid-based dosage form than for a powder or a solid, since a liquid-based dosage form is more likely 
to interact with the packaging components. World Health Organization (WHO, 2002) in its 36th report on 'WHO expert committee on specifications for pharmaceutical preparations' (Annex-9 Guidelines on packaging for pharmaceutical products) proposes some parameters that must be printed on the secondary packaging items. These are, for example, (a) the name of the product, (b) a list of the active ingredients showing the amount of each present and a statement of net contents, e.g. number of dosage units, mass or volume, (c) the batch number assigned by the manufacturer, (d) the expiry date in an uncoded form, (e) any special storage conditions or handling precautions that may be necessary, (f) the directions for use, and any warnings and precautions that may be necessary, (g) the name and address of the manufacturer or the company or person responsible for placing the product on the market. These are the generalized parameters and can only be advisory but the precise information that should be printed on the secondary packaging items must be specified by respective national legislation. At present a large number of pharmaceutical products of different manufacturers are available in the local market under various brand names. The physicians, pharmacists, nurses and community health workers as well as the end users largely rely on the information provided by the manufacturers on the labeling of these products. So, importance of proper labeling is high.

\section{Materials and Methods}

In this research work labels, inner cartoon and direction slip of different drugs from the selected generics available in the local market were collected and thoroughly examined. Various packaging materials of 150 different brands from 50 different generics were selected. The selected generics were: Omeprazole, Ranitidine, Esomeprazole, Pantoprazole, Rabeprazole, Famotidine, Cefixime, Ceftriaxone, Cefradine, Cefuroxime, Cefepime, Paracetamol, Ketorolac, Ibuprofen, Ketoprofen, Caffeine, Diclofenac, Naproxen, Aceclofenac, Etoricoxib, Azithromycin, Clindamycin, Erythromycin, Clarithromycin, Ciprofloxacin, Levofloxacin, Gemifloxacin, Gatifloxacin, Moxifloxacin, Clonazepam, Pregabalin, Valproic Acid, Carbamazepine, Gabapentin, Levetiracetam, Phenobarbital, Cetirizine, Levocetirizine, Fexofenadine, Desloratadine, Loratadine, Amoxicillin, Clavulanic Acid, Ampicillin, Ciprofloxacin,
Flucloxacillin, Bromazepam, Alprazolam, Clobazam, Diazepam (from Antiulcerants, Cephalosporins \& combinations, Non-Narcotic Analgesics, NSAIDs, Macrolides \& similar type, Fluoroquinolones, AntiEpileptics, Antihistamines, and Broad Spectrum Penicillin and Tranquillizers classes of therapeutics). Among these 150 brands, different dosage forms were included such as oral solid, oral liquid, ophthalmic products, inhalers and incjectables.

Following 28 parameters were selected for examining the packaging materials. Among these 28 parameters, 16 parameters were used to determine the regulatory compliance which are: Trade name, Generic name, Name of the manufacturer, Full mailing address of the manufacturer, Manufacturing date, Expiry date, Batch No. /Lot No, Manufacturing License No., Product License No. (DAR no.), Price, Sterility statement, Supply of the label or insert, How supplied (packaging quantity), Volume of the product, Bilinguality and Dosage form (delivery system). The rest of the 12 parameters were examined to find out the extent of clinical information provided in the packaging which are: Composition, Mechanism of action (Pharmacology), Indication, Dosage and administration, Contraindication, Adverse/Side effect, Instruction for use, Storage condition/Pharmaceutical precaution, Overdose, Drug interaction, Instruction for pediatric/geriatric dose and Use in pregnancy and lactation. All the samples were thoroughly checked against these parameters and the findings were recorded and presented in a tabular form.

\section{Results and Discussion}

Among the selected 150 drugs 50 were oral solids (tablets and capsules), 30 were oral liquids (syrup, suspension), 30 were ophthalmic products, 20 were inhalation products and 20 were injectable products. At first the data presented in table- 3 shows the percent occurrences of packaging parameters of the drug products based on the regulatory and general parameters and in table- 4 data of the drug products were presented on the basis of clinical parameters.

It was observed that many pharmaceutical companies in the supplied inserts mentioned "More details are available on request" but most of the pharmaceutical companies did not provide their full mailing or web address. Some of the pharmaceutical companies 
mentioned their address like- "X" pharmaceutical Ltd., Dhaka, Bangladesh. At present, web address is also necessary for communication with the manufacturer, which was not provided in the packaging of most of the products. Many of the manufacturers did not mention information about sterility statement, instruction for pediatric/geriatric use while this information is very important for safe and effective use of drug preparations (Carter, 1987). Side effects, contraindications and storage conditions/ pharmaceutical precautions were also not mentioned in the labeling of a considerable percentage of products. Kenagy and Stein (2001) discussed the medical errors associated with naming, labeling and packaging of pharmaceuticals. They observed that sound-alike and look-alike drug names and packages can lead pharmacists and nurses to unintended interchanges of drugs that can result in patient injury or death. They opined that human factors such as simplicity, standardization, differentiation, lack of duplication and unambiguous communication etc. have often been ignored in drug naming, labeling and packaging. The present study revealed that the secondary packaging item of the selected pharmaceutical products available in Bangladesh lacks several important information, especially in terms of clinical importance. The lack of clinically important information such as adverse effects, contraindications, overdose, warnings/ precautions, drug interactions, use in pregnancy and lactations etc. on the secondary packaging items is very unfortunate and unwanted. It was evident from the study, that the information provided in the packaging in terms of regulatory parameters were more satisfactory compared to that of clinical parameters.

\section{Table 3. Percent occurrences of selected parameters}

\begin{tabular}{lc}
\hline Regulatory \& general Parameters & \% occurrences \\
\hline Trade name & 100 \\
Generic name & 100 \\
Name of the manufacturer & 100 \\
Full mailing address of the manufacturer & 18 \\
Manufacturing date & 100 \\
Expiry date & 100 \\
Batch No./Lot No & 100 \\
Manufacturing License No. & 100 \\
Product License No. (DAR no.) & 100 \\
Price & 100 \\
Sterility statement & 82 \\
Supply of the label or insert & 78 \\
How supplied (packaging quantity) & 100 \\
Volume of the product & 100 \\
Bilinguality & 73 \\
Dosage form (delivery system) & 100 \\
\hline
\end{tabular}

Table 4. Percent occurrences of selected parameters for different dosage forms

\begin{tabular}{|c|c|c|c|c|c|}
\hline Dosage Form & $\begin{array}{c}\text { Oral Solid } \\
(\mathrm{n}=50)\end{array}$ & $\begin{array}{l}\text { Oral Liquid } \\
\quad(\mathrm{n}=30)\end{array}$ & $\begin{array}{l}\text { Opthalmic Product } \\
(\mathrm{n}=30)\end{array}$ & $\begin{array}{l}\text { Inhaler } \\
(\mathrm{n}=20)\end{array}$ & Injectable $(n=20)$ \\
\hline Clinical parameters & & & \%Occurrences & & \\
\hline Composition & 100 & 100 & 100 & 100 & 100 \\
\hline Mechanism of action (Pharmacology) & 70 & 55 & 40 & 45 & 90 \\
\hline Indication & 100 & 100 & 100 & 100 & 100 \\
\hline Dosage and administration & 100 & 100 & 100 & 100 & 100 \\
\hline Contraindication & 97 & 80 & 85 & 95 & 98 \\
\hline Adverse/Side effect & 100 & 95 & 97 & 100 & 100 \\
\hline Instruction for use & 55 & 90 & 100 & 100 & 100 \\
\hline $\begin{array}{l}\text { Storage condition/Pharmaceutical } \\
\text { precaution }\end{array}$ & 100 & 100 & 100 & 100 & 100 \\
\hline Overdose & 100 & 95 & 70 & 100 & 100 \\
\hline Drug interaction & 100 & 100 & 100 & 100 & 100 \\
\hline Instruction for pediatric/geriatric dose & 70 & 85 & 65 & 90 & 95 \\
\hline Use in pregnancy and lactation & 75 & 67 & 72 & 100 & 100 \\
\hline
\end{tabular}




\section{Conclusion}

The present study indicates that packaging information of many pharmaceutical products available in the local market have some lackings about which the practicing pharmacists and regulatory authority should take necessary actions for the betterment of healthcare system of Bangladesh.

\section{References}

Carter SJ (ed.) 1987. Cooper and Gunn's Dispensing for Pharmaceutical Students, $12^{\text {th }}$ edn., CBS Publishers \& Distributors, Delhi, India, p. 645.

Directorate General of Drug Administration 2012, Ministry of Health \& Family, Welfare, Government of the People's Republic of Bangladesh, viewed 10 July 2012, http://www.dgda.gov.bd

DiVito M.P. et al. 1992. American Laboratory, 24, 130-136.
European Commission Enterprise and Industry DirectorateGeneral 2008, Guidelines on the packaging information of medicinal products for human use authorized by the community, Brussels.

European Pharmacopoeia, $4^{\text {th }}$ edn., Council of Europe, Strasbourg 2001. p. 242.

IMS Health; 2011.

Kenagy J.W. and Stein G.C. 2001. Naming, Labeling and Packaging of Pharmaceuticals. Am. J, Health-System Pharmacy, 58, 2033-2041.

Review On: The Pharmaceutical Packaging 2012, Pharmacy Infopedia, viewed 10 July 2012, http://www.pharmatutor. org

The $36^{\text {th }}$ report of WHO expert committee on specifications for pharmaceutical preparations, WHO technical report series 902, 2002, pp.119-145. 